\title{
Single Source FAcility Location Problem Using Genetic Algorithm
}

\author{
LAI, K. T.; LUONG, L. H. S. \& MARIAN, R. M.
}

Abstract: Single source capacitated facility location problems (SSCFLP) are basic location-allocation models used in the optimal design of supply chain, computer network and transmission power, amongst others. While genetic algorithm (GA) has been successfully applied to many combinatorial optimization problems, it has limited success when applied to solving SSCFLP. This paper proposes a GA solution which adopts an integer-based chromosome encoding approach using roulette wheel selection to allocate the alleles in the chromosome. A case study is conducted which shows that the algorithm is capable of solving the problem within short computational time.

Key words: genetic algorithm, single source capacitated facility location problem, roulette wheel selection, integer-based chromosome representation
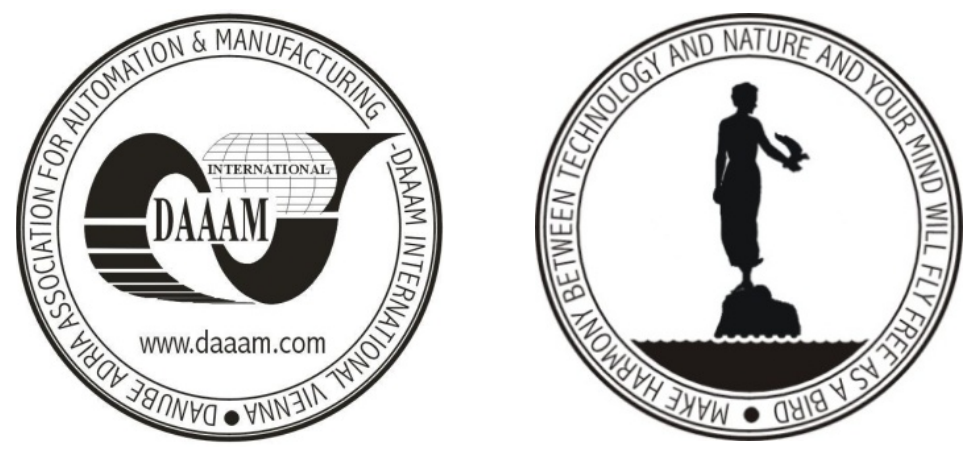

Authors' data: BEng (Hons). BCom. MCom (Hons). Lai, K[im] T[eng]; BEng (Hons). PhD. Professor Luong, L[ee] H. S.; BEng (Hons). MSc. PhD. Marian, R[omeo] M., School of Advanced Manufacturing \& Mechanical Engineering, University of South Australia, Mawson Lakes Campus, Mawson Lakes, SA 5095, Australia,_Laikt004@students.unisa.edu.au,_Lee.Luong@unisa.edu.au, romeo.marian@unisa.edu.au

This Publication has to be referred as: Lai, K[im] T[eng]; Luong, L[ee] H. S. \& Marian, R[omeo] M. (2009). Single Source Facility Location Problem Using Genetic Algorithm, Chapter 36 in DAAAM International Scientific Book 2009, pp. 341-348, B. Katalinic (Ed.), Published by DAAAM International, ISBN 978-3-901509-69-8, ISSN 1726-9687, Vienna, Austria

DOI: $10.2507 /$ daaam.scibook.2009.36 